\title{
Gestão da informação, comunicação científica e internacionalização
}

\section{Information Science, scholarly communication and internationalization}

\author{
Paula Carina de Araújo ${ }^{1}$, Maria do Carmo Duarte Freitas ${ }^{2}$, Helza Ricarte Lanz ${ }^{3}$ \\ ${ }^{1}$ Universidade Federal do Paraná (UFPR), Curitiba, Paraná, Brasil. ORCID: https://orcid.org/0000-0003-4608-752X \\ 2 Universidade Federal do Paraná (UFPR), Curitiba, Paraná, Brasil. ORCID: http://orcid.org/000-0002-7046-6020 \\ ${ }^{3}$ Universidade de Colônia, Colônia, Alemanha. ORCID: https://orcid.org/0000-0002-6739-2868
}

Autor para correspondência/Mail to: Paula Carina de Araújo, revistaatoz@ufpr.br

Copyright (C) 2021 Araújo, Freitas \& Lanz. Todo o conteúdo da Revista (incluindo-se instruções, política editorial e modelos) está sob uma licença Creative Commons Atribuição 4.0 Internacional. Ao serem publicados por esta Revista, os artigos são de livre uso em ambientes educacionais, de pesquisa e não comerciais, com atribuição de autoria obrigatória. Mais informações em http://revistas.ufpr.br/atoz/about/submissions\#tcopyrightNotice.

O volume 10, número 2 da AtoZ é um retrato da diversidade da sua produção científica e demonstra a sua inserção internacional. Esse fascículo contém três artigos de autores de instituições de Portugal, Equador, Espanha e Estados Unidos. Destacamos que a equipe editorial da AtoZ tem focado em ações que caracterizem a revista como uma publicação que promove a ciência aberta, a publicação de pesquisas interdisciplinares e a diversidade de temas, autores, instituições e países.

Parte-se desses princípios, para destacar a entrevista sobre "A ciência e a cientista de dados" concedida por Renata Cristiana Gutierres Castanha que atua na Anheuser Busch Inc. (AMBEV) e tem uma atuação híbrida como pesquisadora e cientista de dados. A entrevistada respondeu perguntas sobre o conceito, a aplicação e projetos de ciência de dados, bem como sobre a sua atuação na área.

Essa edição também contém duas pesquisas relacionadas à temática dos dados. O artigo "Dados abertos governamentais: iniciativas e desafios na abertura de dados no Brasil e outras esferas internacionais" contextualiza o movimento histórico de abertura de dados e evidencia suas contribuições em relação aos desafios e oportunidade para os governos. A partir de outra perspectiva, o estudo de caso "Visualização de dados para extração de conhecimento" avalia a implantação de ferramentas de data mining visual em uma startup de seguros para smartphones.

Outra temática evidenciada nesta edição é a dos estudos métricos da informação. As relações e influências da epistemologia social no Brasil são o foco de um estudo bibliométrico que analisou indicadores relacionais de citação e cocitação de autores que busca averiguar os principais influentes da temática na produção científica nacional. Em outra pesquisa, a rede de comunicação dos docentes do curso de mestrado em Ciências da Documentação e Informação da Faculdade de Letras da Universidade de Lisboa é mapeada e também são discutidos conceitos e métodos como rede social, coautoria, análise de rede social e análise bibliométrica.

Enfatizamos o artigo "Clareza, concisão e coesão: princípios e métricas de legibilidade aplicados ao texto de pós-graduandos em ciência da informação", também relacionado à temáticas dos estudos métricos da informação que foi anteriormente depositada como preprints. A pesquisa questiona qual o impacto da aplicação de princípios de clareza, concisão e coesão na extensão e legibilidade de textos científicos e objetiva verificar esse impacto ao comparar extensão e indica-dores de legibilidade antes e após a aplicação dos princípios e discute um tema importante e re-levante para a comunicação científica.

Este fascículo também traz dois artigos internacionais relacionados a questões de ensino em ambiente digital. O artigo "Usando ClassDojo para motivar a participação de crianças nas aulas online de inglês durante a pandemia da COVID-19" apresenta uma perspectiva dos alunos e investiga a influência da ferramenta ClassDojo na participação de alunos equatorianos durante as aulas de inglês online. Sob outra perspectiva, a pesquisa "Atitudes dos professores em relação a ambiente de aprendizagem personalizados" apresenta outra perspectiva e identifica essas atitudes e fatores que determinam a sua aceitação ou rejeição a esses novos contextos. Apresentamos ainda outros três artigos publicados neste fascículo e que discutem temáticas fundamentais para a gestão da informação.

A possibilidade de a Ciência da Informação (CI) se sustentar em um discurso epistêmico transdisciplinar é discutida na pesquisa "Ciência da Informação: uma utopia transdisciplinar" e representa uma importante reflexão para e sobre a epistemologia dessa área. Em outro artigo, uma pesquisa bibliográfica identifica os elementos da cultura organizacional que impactam a gestão do conhecimento para inovação de processos em serviços no artigo. Para completar os 10 artigos publicados nesta edição, apresentamos a pesquisa "Fatores-chave para o projeto de sistemas integrados de gestão de informação para bibliotecas universitárias" que identifica os fatores design intuitivo, flexibilidade, interconexão e portabilidade como chave para o design de sistemas integrados de bibliotecas nas universidades. 
Por fim, esta edição traz como novidade, a publicação da palestra "Respirando fundo: pressões e saúde na jornada do pesquisado", proferida pela Dra. Eneida Regina Fabian Holzmann durante o Consórcio Mestral e Doutoral do Programa de Pós-graduação em Gestão da Informação (PPGGI) da Universidade Federal do Paraná (UFPR).

Este fascículo consolida as ações desenvolvidas pela equipe editorial da AtoZ para fazer parte do movimento de ciência aberta e possibilitar a disseminação de conhecimento relacionado à gestão da informação de forma interdisciplinar. A diversidade de temas, autores, instituições e países neste fascículo e a publicação de artigo que foi disponibilizado anteriormente como preprint demonstram as ações desenvolvidas até aqui e permitem finalizar este editorial destacando esses diferenciais da AtoZ.

Boa leitura,

As Editoras.

Curitiba, maio de 2021. 